\title{
Mulher, Prostituta e Prostituição: da História ao Jardim do Éden.
}

\author{
Thaís Zimovski Oliveira, \\ Universidade Federal de Minas Gerais - Brasil \\ thais.zimovski@yahoo.com.br \\ Ludmila Vasconcelos Guimarães, \\ Centro Federal de Educação Tecnológica de Minas Gerais - Brasil \\ vmguimaraes@hotmail.com \\ Debora Pazzeto Ferreira \\ Centro Federal de Educação Tecnológica de Minas Gerais - Brasil \\ deborapazetto@gmail.com
}

\section{Resumo}

O presente estudo teve como objetivo compreender a articulação da construção histórica da prostituição no contexto patriarcal e suas conexões com o valor simbólico da representação feminina em um mito religioso, a saber, o mito de Lilith. A fim de trazer essa discussão para o contexto atual, apresentamos falas de prostitutas de baixo meretrício entrevistadas em Belo Horizonte, a partir dos fundamentos teóricos da metodologia de "história de vida". Para realizar esta reflexão, valeu-se da noção de Levi Strauss (1978) acerca do mito enquanto manifestação simbólica do contexto social. Além disso, traçou-se um breve panorama histórico no qual são destacados alguns momentos importantes para o desenvolvimento da prostituição. Em seguida, foram observados aspectos legais e políticos da atualidade que circundam, sobretudo, as questões trabalhistas das prostitutas no Brasil. A partir dessa explanação, retomou-se os trechos das narrativas de vida das prostitutas entrevistadas, para analisá-los tendo como base tanto o contexto tratado neste artigo, quanto a leitura que reforça a posição subserviente da mulher nos contos religiosos, em especial, a figura mítica de Litith.

Palavras-chave: mulher, prostituição, história de vida, mito. 


\title{
Woman, Prostitute and Prostitution: From History to Garden of Eden
}

\author{
Thaís Zimovski Oliveira, \\ Universidade Federal de Minas Gerais - Brasil \\ thais.zimovski@yahoo.com.br \\ Ludmila Vasconcelos Guimarães, \\ Centro Federal de Educação Tecnológica de Minas Gerais - Brasil \\ vmguimaraes@hotmail.com \\ Debora Pazzeto Ferreira \\ Centro Federal de Educação Tecnológica de Minas Gerais - Brasil \\ deborapazetto@gmail.com
}

\begin{abstract}
The present paper aims to understand the link between the historical construction of prostitution in a patriarchal context and the symbolic value of female representation in a religious myth (the myth of Lilith). In order to bring this discussion to the present context, we present some prostitutes narratives that were interviewed in a poor area of a Brazilian city called Belo Horizonte using methodology of "life history". For the purpose of this discussion, it was applied Levi Strauss's notion of myth as a symbolic manifestation of the social context. In order to carry out this articulation, a brief historical overview was drawn up in which important moments for the development of prostitution are highlighted. Afterwards, we observed some legal and political aspects of the times that surround, above all, the labor issues of prostitutes in Brazil. Based on this discussion, we have pointed to excerpts from the prostitute's life histories, which were analyzed based on the socio-context and in the theoretical approach we directed to the myth of Lilith, considering mainly how it may reinforces the subservient position of women in religious tales.
\end{abstract}

Keywords: woman, prostitution, life history, myth. 


\section{Introdução}

Pensar na construção do papel da mulher na sociedade é também refletir sobre o patriarcalismo․ Para explicar essa ligação, Gerda Lerner (1986), uma das precursoras das pesquisas históricas sobre a mulher, aponta o fato de o mundo ocidental ter se originado após a criação e consolidação do sistema patriarcal nas primeiras civilizações humanas. Desde a década de setenta, movimentos feministas alertam para o fato de que as culturas patriarcais em que vivemos são indissociáveis da transformação da mulher em objeto do desejo masculino, seja como serva doméstica, como dona de casa, como esposa, como procriadora ou como prostituta (Jaggar \& Bordo, 1997).

Essa estrutura atravessa o imaginário coletivo do machismo ${ }^{2}$, mesmo que de modo inconsciente, sendo reforçada atualmente pela mídia de massas e pela negação de que o corpo da mulher pertence a ela própria. É tão antiga que pode ser encontrada nas primeiras mitologias do patriarcado, como o mito de Lilith - a primeira mulher de Adão, que teria sido apagada do conto da criação na bíblia e substituída por Eva. De acordo com algumas vertentes da mitologia judaica, a primeira mulher de Adão não foi Eva, mas Lilith, criada igualmente por Deus, a partir do barro. Diferentemente de Eva, cuja história permanece na bíblia, Lilith não teria se sujeitado à dominação de Adão. Assim, além de ter sido banida do paraíso, tornando-se uma imagem demonizada, reaparece em algumas narrativas como a serpente do Éden.

Historicamente, a mulher apresenta-se em um primeiro momento como divindade , tendo sua trajetória marcada por rituais sagrados de fertilidade (Matos \& Soihet, 2003; Conceição, 2007). Conforme as civilizações se consolidavam, a dominação masculina sobre a mulher instaurava-se, sendo reforçada pela religiosidade. Assim, o respeito atribuído às mulheres foi pouco a pouco moldado em função de sua subserviência, de modo que a

\footnotetext{
${ }^{1}$ Utilizaremos neste artigo, a palavra patriarcalismo com o significado apresentado por Osterne (2012, p.131): "sistema masculino de opressão das mulheres, caracterizado por uma economia domesticamente organizada, na qual as mulheres tornam-se objeto de satisfação sexual dos homens, reprodutoras de herdeiros, de trabalho e de novas reprodutoras."

${ }^{2}$ Ainda de acordo com Osterne (2012), a naturalização dos privilégios masculinos e a subordinação social do feminino são a dimensão cultural que configura o próprio conceito de machismo e é a partir disso que se institui na sociedade o "preconceito desfavorável contra o feminino" (p. 132).
} 
mulher que não tivesse sua "proteção" garantida por um homem era tida como prostituta 3 ou “não-respeitável” (Lerner, 1986). O estigma e exclusão construídos historicamente pela sociedade patriarcal em relação à mulher permanecem até os dias atuais, em que relatos de abandono pelo pai, ou pelo parceiro são frequentemente apontados, por exemplo, nas falas de prostitutas de baixo meretrício de Belo Horizonte, entrevistadas especialmente para este trabalho.

Tendo em vista esse cenário social, religioso, econômico, institucional, legal, simbólico, imaginário e psíquico do patriarcado, este artigo visa compreender a articulação da construção histórica da prostituição no contexto patriarcal e suas conexões com valor simbólico da representação feminina em um mito religioso, a saber, o mito de Lilith. A fim de trazer essa discussão para o contexto atual, apresentamos falas de prostitutas de baixo meretrício entrevistadas em Belo Horizonte. Essa proposta nos permite, inclusive, pensar em aspectos da situação da mulher na sociedade que não se limitam a questão da prostituição. Contudo, é importante destacar que essa situação é constituída por múltiplas dimensões, que estão além da representação da imagem feminina na mitologia. Além disso, reconhecemos que este cenário, de forma alguma, pode ser visto como um espaço homogêneo e livre de antagonismos políticos, de modo que, considerar uma categoria universal de mulher, independentemente das particularidades de raça, gênero, território, classe social e sexualidade seria um equívoco (Hirata, 2014). No entanto, a representação da mulher na mitologia, contrapondo-a a falas de prostitutas de baixo meretrício da atualidade mostrou-se como um caminho frutífero e interessante para ilustrar possíveis conexões entre a mitologia, enquanto manifestação simbólica do contexto social (Strauss, 1978) e a manutenção da dominação do feminino pelo sistema patriarcal.

Não se sabe ao certo a qual período histórico remete-se a origem da prostituição. Entretanto, pode-se perceber a existência dessa prática nas mais distintas culturas e sociedades do mundo atual. Desde as isoladas províncias chinesas submetidas ao controle ditatorial de governantes que visam reprimir não apenas a prostituição, mas toda a sexualidade feminina (Cao \& Stack, 2010), passando por peculiares povos asiáticos como os

\footnotetext{
3 A palavra "prostituta" foi escolhida ante "profissional do sexo", pois esta segunda por si só exprime uma posição que compreende o trabalho sexual como uma profissão, posicionando-se ideologicamente de acordo com o regulamentarismo - linha que será abordada na seção "Posicionamentos legais em relação à prostituição".
} 
Badi no Nepal, para os quais a prostituição é naturalizada e tratada como norma social (Cox, 1992), até os países mais economicamente desenvolvidos da Europa, onde ela pode ser, inclusive, legalizada (Oliveira, 2008).

De modo geral, a prostituição costuma ser dividida em duas categorias bastante distintas: "luxo" e "baixo meretrício". As diferenças encontradas em cada um desses grupos configuram realidades que dificilmente podem ser comparadas. Na prostituição de baixo meretrício é comum que o ingresso das mulheres ocorra em função da urgência pelo sustento dos filhos, ou pela busca de sua própria sobrevivência (Moreira, 2009). Por exemplo, mulheres que por algum motivo estão desabrigadas, ou em situação de miséria, podem encontrar nos prostíbulos uma possibilidade de sair das ruas. Normalmente, realizam suas atividades em casas ou hotéis localizados nas regiões mais pobres dos centros das cidades, as chamadas zonas de meretrício. Em alguns casos, a própria prostituta paga um valor diário pelo uso do quarto, em outros, ela pode repassar ao dono(a) da casa certa porcentagem da renda auferida durante o período.

Por outro lado, as prostitutas de luxo, ou garotas de programa, são mulheres que encontram seus clientes em bairros de classe alta da cidade, por meio de sites, catálogos de modelos, boates, bares ou clubes de striptease. Muitas dessas mulheres fazem curso superior e realizam programas de duração mais longa, e não apenas sexuais, podendo ser contratadas, inclusive, como acompanhantes executivas. Elas prezam por manter a discrição demandada pela maioria dos clientes e, com essa finalidade, realizam todos os seus contatos por uma linha de telefone à parte. Dessa forma, ainda conseguem manter certo afastamento entre o trabalho e sua vida pessoal como destaca Moreira (2009). Outros autores, como Andrade e Teixeira (2004), no entanto, apontam que, apesar de aparentarem possuir uma boa condição financeira, muitas dessas moças são, na realidade, de famílias pobres. Além disso, mesmo cobrando mais caro pelos programas, podem ficar muito tempo sem conseguir clientes e, ainda precisam empregar muitos recursos financeiros para manter a boa aparência.

De acordo com Ceccarelli (2008), no entanto, esses dois tipos de prostitutas são separadas não apenas por fatores físicos externos, como a aparência ou o preço cobrado, mas, sobretudo pelas "posições subjetivas" por elas ocupadas. Ou seja, pela interpretação delas mesmas a respeito de suas atividades e, por conseguinte, na construção de sua 
autoimagem: "As scort girls", por pertencerem, na grande maioria das vezes, ao mesmo universo social que seus clientes, estabelecem com a prostituição uma relação bem diferente da prostituta do baixo meretrício, muitas vezes nem cumprimentada na rua”. (Ceccarelli, 2008, p.7).

Como o presente texto parte de uma série de entrevistas com mulheres que desenvolvem suas atividades de prostituição na principal zona de baixo meretrício da cidade de Belo Horizonte, o foco aqui, naturalmente, não é a prostituição de luxo. Trata-se, antes, de abordar essas entrevistas com prostitutas de baixo meretrício na tentativa de compreender a relação entre a prostituição e as culturas patriarcais, associadas às práticas ou à moral religiosa, que podem, dentre outros fatores, determinar a posição que a mulher ocupa na sociedade.

Tendo em vista esta proposta, é importante destacar que o serviço sexual remunerado tem sua origem em sociedades patriarcais antigas, nas quais as mulheres que não eram relacionadas a algum homem eram tratadas como prostitutas. Essa herança histórica se faz presente na prostituição - bem como como machismo cotidiano percebido nos mais diversos contextos sociais - até os dias atuais (Lerner, 1986). Assumindo a centralidade das organizações na estrutura social pós-industrial (Braverman, 1987), a administração de empresas não deve ser vista como um campo isento e livre de implicações nesta dinâmica social. Dessa forma, parte-se do conceito de administração apontado por Whittington (2004), em que a retrata, sobretudo no contexto pós moderno, como algo que se relaciona mais à prática social do que a técnicas ilusoriamente imparciais que desconsideram uma análise engajada da sociedade.

Assim, partiremos na próxima seção para um resgate histórico, ainda que sucinto e sumarizado de alguns pontos que marcaram o desenvolvimento da história da prostituição, para então propor meios de compreender o papel simbólico do mito da sociedade e mostrar como estes aspectos estão presentes na realidade atual.

\footnotetext{
4 Prostitutas de Luxo
} 


\section{A prostituição na história}

Como mencionado anteriormente, não há um consenso em relação ao período em que é datada a origem da prostituição, entretanto, partiremos dos primeiros rumores que envolvem o tema. Na formação das primeiras civilizações humanas, a prostituição teve um papel importante. Vale destacar, contudo, que para analisarmos sua evolução devemos levar em conta as diferentes concepções morais existentes entre a contemporaneidade e a antiguidade (Bullough \& Bullough, 1987). Alguns historiadores apontam, por exemplo, que em certas culturas antigas podia-se encontrar um senso de hospitalidade em que mulheres eram oferecidas a forasteiros como forma de "boas vindas". É o caso dos Fenícios de Heliópolis, descrito por Eusébio de Cesaréia no século IV d.C. , em que os homens ofereciam as próprias filhas para satisfazer sexualmente seus visitantes5 (Ullmann, 2005).

Desse modo, nota-se que tanto as relações de poder sob as quais pautava-se o sexo na antiguidade quanto os valores morais daqueles povos eram diferentes dos que operam atualmente em nossa cultura ocidental. É nesse sentido que devemos compreender a chamada "prostituição sagrada", ou "prostituição de culto", a qual consistia em rituais que aconteciam em diversas regiões da antiga mesopotâmia nos últimos séculos anteriores a Cristo. Um dos ritos mais lembrados é a alegórica história relatada por Heródoto no ano de 500 a.C., a qual descreve como todas as mulheres nascidas no país deveriam ir ao menos uma vez na vida até o templo da cidade e, em adoração à deusa Afrodite, ter relações sexuais com um homem estranho. O que causa mais espanto em relação a essa história, especificamente, é que as mulheres consideradas feias eram submetidas a uma longa espera até que um homem as escolhesse. Algumas, sem poder sair do templo, esperavam por cerca de três a quatro anos, ao passo que as mulheres mais bonitas eram rapidamente escolhidas, tendo assim a oportunidade de cumprir o sacrifício religioso a elas designado (Lerner, 1986).

Além desse relato, há ainda outros que apontam para a religiosidade antiga como origem da prostituição. Entre os Sírios, por exemplo, em decorrência das comemorações festivas em adoração ao deus Adonis, todas as mulheres eram coagidas a se prostituir (Ullmann, 2005). Entretanto, também se deve levar em conta que o próprio relato de

\footnotetext{
5 Não analisaremos este fenômeno como estupro, sob a ótica dos valores éticos e morais da atualidade, pois isso configuraria uma situação de “anacronismo histórico" (Foucault, 1984).
} 
Heródoto apresenta uma mudança no processo histórico da prostituição, já que uma mulher não tinha o direito de recusar o dinheiro a ela oferecido ou rejeitar algum homem.

Vale lembrar que o período conhecido como Antiguidade é marcado pela sucessiva emergência e declínio de diversas civilizações, começando pelos sumérios por volta de 5 mil a.C., passando pelos Assírios no último milênio a.C., até a queda do Império Romano do Ocidente em 476 d.C. No decorrer desse processo histórico, a posição da mulher na sociedade foi se transformando, assim como as suas liberdades. Firmavam-se aos poucos os alicerces culturais de uma cultura patriarcal, em que a mulher, antes relacionada a deusas da fertilidade, passa a ser submetida ao controle masculino.

$\mathrm{Na}$ medida em que a sociedade foi se tornando mais militarizada, as regras sociais ficaram mais rígidas. Entre os anos 600 a 900 a.C., instaurou-se na Mesopotâmia uma lei acerca do uso véu, que até os dias de hoje influencia algumas culturas orientais - vê-se claramente no uso da burca. Esta lei, chamada "Lei 40 do Código Assírio", era um esforço para distinguir as mulheres sob a proteção de um homem daquelas consideradas "públicas": as mulheres respeitáveis tinham o direito de usar este véu, enquanto as "não respeitáveis" tinham o seu uso fortemente proibido. De acordo Lerner (1986), essa foi a primeira vez em que a classificação social entre as mulheres foi dada pela sua sexualidade, já que o véu "não distinguia a mulher livre da mulher escrava, ou classes altas das classes baixas" (Lerner, 1986, p. 248, tradução nossa); a distinção era claramente baseada na relação que essas mulheres tinham com um homem, e o véu era usado como "emblema da mulher casada" (p.248, tradução nossa).

Mais especificamente, a "Lei 40 do Código assírio" consistia em uma severa e agressiva punição física às mulheres "não respeitáveis" que usassem o véu. Ademais, para que o Estado atingisse esse objetivo, a lei fazia com que os homens punissem as mulheres que estivessem usando o véu indevidamente. Ainda, havia na lei uma punição destinada aos homens que, por qualquer razão, se omitissem em delatar tais mulheres. Não se sabe ao certo a razão pela qual era necessário o estabelecimento dessa punição. Possivelmente porque os homens da época não eram tão coniventes com essa imposição legal.

No entanto Lerner (1986) argumenta que o intuito principal da lei não era negar às prostitutas o uso do véu, mas, sobretudo, preservar os homens do convívio difamador com essas mulheres. Como distinguir uma mulher sob o véu, que cobre toda sua face, é 
praticamente impossível, a lei conferia ao homem esta responsabilidade, já que este, ao acompanhá-la, certamente estaria a par de sua posição social. Assim sendo, para a autora, "ter que aparecer em público não usando o véu iria imediatamente identificar a mulher como uma prostituta e a distinguir das mulheres respeitáveis" (Lerner, 1986, p. 250, tradução nossa). Constrói-se desse modo, aos poucos, mas solidamente, a ideia de que a mulher que não tem ao seu lado um homem que a proteja e que a legitime, que seja seu pai na infância ou seu marido na idade adulta, é pública, indigna, não respeitável, prostituta.

Nessa conjuntura, cada vez mais a prostituição sagrada cedia lugar para a prostituição comercial que vinha se desenvolvendo sobretudo a partir da exploração sexual de escravas e do tráfico de crianças. Nessa época era comum que homens pobres, que estivessem prestes a ser escravizados por dívidas contraídas em períodos de fome, vendessem suas filhas virgens em troca de algum retorno financeiro. O mesmo tipo de exploração sexual também poderia ser feita por maridos com a finalidade de escapar da escravidão. Dessa forma, "por volta do meio do segundo milênio a.C., [a] prostituição era bem estabelecida como uma provável ocupação para as filhas dos pobres”. (Lerner, 1986, p. 247, tradução nossa).

Pode-se dizer que, da mesma forma em que se deu a transição do trabalho escravo para o trabalho assalariado, ocorreu o processo de transformação da prostituição escravizada em prostituição comercial (Engels, 2009). As influências deixadas por essa história em nossa cultura ocidental são muitas, principalmente porque o contexto patriarcal já estava completamente estabelecido no Oriente quando os povos ocidentais começaram a surgir. O patriarcalismo encontra-se tão enraizado na realidade atual que reflexões visando questionar sua primazia deparam-se com grande resistência, e a prostituição feminina está inegavelmente associada ao patriarcado e às desigualdades sociais de gênero ${ }^{6}$.

Ainda, é fundamental distinguir a exploração sexual, que ocorre sob coerção, da prostituição voluntária de uma mulher que decide se prostituir. Tratar a prostituta sempre como vítima incapaz de tomar decisões por si mesma é subestimá-la. Contudo, ignorar o contexto cultural e social patriarcal - no qual as mulheres ocupam os postos de trabalho

${ }^{6} \mathrm{O}$ Termo desigualdade social de gênero é utilizado para apontar as diferenças estruturais referentes aos âmbitos da economia, trabalho, direitos, tecnologia, segurança e política, que acompanham transformações da sociedade e que podem recair diferentemente sobre indivíduos em função do gênero. Especialmente, compreendendo gênero enquanto uma categoria composta por normas e características atribuídas compulsoriamente a sujeitos dada sua constituição biológica, dicotomizando o ideal de "homem" ou "mulher" como instâncias existentes a priori na essência humana (Butler, 2004; Souza, 2016). 
mais precários, recebem salários cerca de 30\% mais baixos que os homens no desempenho das mesmas funções (Ñopo \& Winder, 2010), são cotidianamente vítimas das mais variadas violências físicas, sexuais, psicológicas e institucionais e são afastadas até mesmo da ideia de autonomia econômica, ainda que muitas vezes sejam abandonadas pelos parceiros e precisem sustentar seus filhos sozinhas - é uma forma de perpetuar a violência das mulheres pelos homens (Hirata, 2010). A prostituição precisa ser abordada como uma questão para o feminismo, para a crítica da cultura patriarcal, e como uma questão política e trabalhista. Nesse sentido, é importante atentar também ao panorama legal referente aos diferentes posicionamentos adotados pelos países na atualidade.

\section{Posicionamentos legais e a prostituição no Brasil.}

Ao menos três correntes podem ser observadas ao se tratar de prostituição: abolicionismo, regulamentarismo e proibicionismo. A primeira entende que a prostituição pode ser considerada como uma exploração sexual, ou seja, uma atividade análoga ao trabalho escravo. O sistema regulamentarista, por sua vez, entende que "a prostituição é atividade legal" (Oliveira, 2008), ou seja, um trabalho como qualquer outro, que deve ser regulamentado, fiscalizado e taxado pelo Estado. Quanto à terceira corrente, Tavares (2006) afirma que o sistema proibicionista é adotado por países mais conservadores e puritanos e baseia-se principalmente em uma concepção moralista, que condena a prostituição e todas as pessoas envolvidas com essa atividade, inclusive a prostituta. Apesar de menos comum, esse sistema é utilizado por países influentes como Estados Unidos e a maioria dos países do Oriente Médio.

Em relação ao contexto brasileiro, as origens da prostituição remontam ao regime escravocrata, sendo que muitas prostitutas na corte imperial eram escravas negras. $\mathrm{O}$ assunto, porém, apenas se tornou uma questão de domínio público devido a uma preocupação médica relacionada ao momento em que mulheres europeias, brancas, passaram a vir para o Brasil e "sem falar o idioma e sem conhecer ninguém, seriam obrigadas a exercer a prostituição" (Pereira, 2005, p.27).

O termo "profissional do sexo" surgiu em meados da década de 1970 para designar as pessoas que se prostituem. Já no ano de 1990, as políticas públicas direcionadas à 
prostituição começaram a mudar devido à emergência de organizações integradas por prostitutas que reivindicavam tanto os direitos sociais de cidadania quanto o reconhecimento da prostituição como uma profissão (Rodrigues, 2009).

De acordo com Rodrigues (2009), a pressão por mudança veio, principalmente, de movimentos em defesa dessa causa, uma vez que as prostitutas enfrentavam forte repressão e violência policial. Essas organizações integradas, posteriormente, transformaram-se em associações e redes nacionais de apoio às profissionais do sexo, e, com isso, iniciaram uma luta perante o congresso nacional, objetivando, sobretudo, descriminalizar a prostituição e buscar seu reconhecimento como forma de trabalho (Rodrigues, 2009).

Atualmente, mesmo que o ato de se prostituir não esteja mais no âmbito criminal, observam-se poucos avanços relativos ao tratamento da sociedade para com as prostitutas especialmente as de baixo meretrício, conforme Barreto (2008). No entanto, as associações representantes do segmento demandam que o trabalho do sexo não tenha diferenças em relação aos outros trabalhos. A prostituição somente foi reconhecida no Brasil como ocupação no ano 2002, quando foi inserida na Classificação Brasileira de Ocupações - CBO (Brasil, 2002).

Para suprir essa demanda, em 2003, o deputado federal Fernando Gabeira criou o projeto de lei n.98/2003. Este projeto permaneceu por muitos anos no plenário e nunca teve sua efetivação. O teor controverso do assunto, provavelmente, foi o que impediu que ele fosse implementado. Em 2012, o deputado Jean Wyllys, retornou com a discussão do assunto criando o PL4.211/20012. Esse PL considera "profissional do sexo toda pessoa maior de dezoito anos e absolutamente capaz que voluntariamente presta serviços sexuais mediante remuneração" (Brasilia, 2012, p.1). O PL também torna o pagamento pelo serviço sexual juridicamente exigível, pessoal e intransferível e possibilita o trabalho em cooperativas ou em casas de prostituição onde não aconteça exploração sexual, fenômeno definido pela PL da seguinte forma:

I- apropriação total ou maior que 50\% do rendimento de prestação de serviço sexual por terceiro;

II- o não pagamento pelo serviço sexual contratado; 
III- forçar alguém a praticar prostituição mediante grave ameaça ou violência. (Brasilia, 2012, p.1)

Se o projeto for aprovado, ele ainda promoverá mais uma significativa mudança na realidade dos profissionais do sexo: irá garantir o direito à aposentadoria especial de 25 anos. Segundo o deputado autor do projeto, Jean Wyllys, essas modificações foram idealizadas por meio de uma pesquisa de campo com as próprias prostitutas e seu conteúdo emergiu de demandas feita por elas. O deputado justifica a criação desta lei considerando que atualmente, no Brasil, há uma grave marginalização e exclusão dessas trabalhadoras: negarlhes os direitos do trabalho é uma injustiça causada por um "moralismo superficial”, o qual, ao mesmo tempo, condena e fomenta a atividade desde seu surgimento (Brasília, 2012).

Por fim, de acordo com Barros (2005), além de carregar o estigma acima mencionado, a prostituição leva consigo uma série de riscos relacionados à exposição das DSTs e, especialmente, às agressões, já que nessa atividade não se sabe ao certo o que esperar do comportamento do cliente. Muitas vezes, as prostitutas estão sujeitas à violência física, abusos sexuais, tráfico, roubos e violência psicológica, como se o pagamento conferisse ao cliente o poder para fazer o que bem entender.

\section{A mulher nos mitos}

Uma das estratégias mais eficazes para se compreender a estrutura implícita de uma cultura é analisar seus mitos fundadores. O senso comum costuma compreender os mitos como algo falso, fantasioso ou exagerado para uma situação. As raízes dessas considerações acerca do mito carregam traços do debate sobre o que é ciência, já que ela é considerada como portadora da verdade. Nesse sentido, tudo que está fora dos limites da ciência, como é o caso dos mitos, acaba carregando o rótulo de falso ou fictício. No entanto, os mitos trazem em si um tipo de verdade, uma verdade simbólica, psíquica, estética, que denuncia os valores mais básicos de uma cultura.

Assim, na contramão do conceito positivista de ciência como o caminho para a verdade, existem estudos que buscam compreender os mitos como forma de explicar fenômenos marcantes da vida como a morte, o nascimento, as doenças, o sexo, os gêneros. Outros estudos se propõem a descrever os mitos como uma forma de controle social que 
pode ser utilizada como guia para as convenções relativas aos comportamentos e relações humanas.

Nos estudos de Levi Strauss (1978), a conceituação de mito vai muito além da explicação de fenômenos marcantes ou de controle social. Fundador da antropologia estrutural, constrói sua obra tendo como base estudos sobre comunidades não civilizadas e defende o mito como uma organização da realidade que possui três funções principais: 1) Função explicativa: o presente pode ser explicado por algo que ocorreu no passado e seus impactos são marcas que se registram no tempo. 2) Função organizativa: entende que o mito organiza as relações sociais afim de manter e legitimar um sistema de regras de convivência social. 3) Função compensatória: ao narrar uma situação passada, o mito nega o presente e isso incorre em uma compensação dos humanos diante de alguma perda ou erro: garantir que o erro do passado foi corrigido no presente.

Considerando que o mito é uma história construída por palavras de uma determinada língua, em um determinado tempo e contexto, Levi Strauss (1978) reconhece que os signos encontrados no mito fazem parte de campos diferenciados da experiência humana no mundo. Portanto, por meio do mito é possível compreender a visão de mundo dos indivíduos, seus valores e formas de se relacionar.

Em relação à mulher, encontramos claramente, nas mais diversas mitologias das sociedades patriarcais, aquilo que o sociólogo francês Pierre Bourdieu chamou de violência simbólica, que é a mais sutil e imperceptível, e por isso mesmo mais eficaz e determinante. Nossa cultura ocidental foi construída através de constantes associações simbólicas e religiosas da imagem da mulher com a da feiticeira (Medeia, Circe), com a da encantadora (sereias, ninfas), com a origem do mal (Eva, Pandora, Helena, Lilith, Tiamat). É preciso aterse a esse poder invisível da linguagem e das imagens para compreendermos a lógica da dominação patriarcal. Essa dominação se impõe como um véu - como o véu assírio que cobre a face das mulheres - que desvia a atenção para contos e fantasias encantadoras, de tal forma que não se percebe sob esse véu mítico a instauração de um imaginário coletivo, que tem efeitos concretos e devastadores, ligado à superioridade abusiva do homem. Os mitos, as histórias infantis, as narrativas e costumes religiosos estabelecem como uma ordem quase inexorável o destino das mulheres como passivas, pecadoras e dependentes do homem para serem protegidas e legitimadas em sua existência. Isso está na Bíblia, na Teogonia, de 
Hesíodo, e na Odisséia e Ilíada, de Homero, nas histórias infantis medievais, bem como na mídia e na cultura de massas contemporânea, que continua transformando diariamente o corpo da mulher em objeto de consumo.

A retomada da potência dos mitos neste estudo é importante para analisarmos como as histórias de Lilith e Eva são construídas tendo em vista a tradição religiosa. Essas histórias podem ser consideradas como mitos pois são falas carregadas de significado em que é possível fazer analogias. Assim, evidencia-se a relação desses mitos com a construção social do papel da mulher, e portanto abre a possibilidade de compreensão dos estigmas determinados a este papel quando não se está sob a "proteção" de um homem.

\section{Lilith e Eva}

Considerado como um texto dos evangelhos apócrifos e não reconhecido pelo cristianismo ortodoxo, o mito de Lilith pertence à tradição rabínica de transmissão oral, conforme Gomes e Almeida (2007). Para Engelhard (1997), a figura feminina de Lilith pode ser encontrada nas mitologias sumeriana, babilônica, assírica, cananéia, hebraica, árabe, persa e teutônica, mas é rejeitada pela cultura e religião tradicional e patriarcal.

Sicuteri (1986) narra que Lilith foi uma mulher criada por Deus logo após Adão no final do sexto dia. Enquanto Deus descansava no sétimo dia - dia sagrado para os hebreus Adão e Lilith consumaram sua relação na escuridão do Sábado. Assim, a potência feminina/demoníaca é sentida pelo homem como algo que provoca prazer e descontrole da situação, conforme Rodrigues (2007). A relação se constitui intensa e caracterizada por um amor que foge ao controle da dimensão divina: uma perfeita complementação (Rodrigues, 2007). Justamente neste ponto é que se aparece o marco da perturbação do universo masculino: o macho perde o controle na relação e a intimidade com o Criador é ferida já que o amor apresentado pela mulher é igualmente intenso e possui dimensão semelhante ao amor de Deus. Contudo, a união carnal/sexual de Lilith e Adão se torna-se perturbadora quando Adão decide que na relação sexual Lilith deve permanecer por baixo e ele por cima:

Assim perguntava a Adão: '- Por que devo deitar-me embaixo de ti? Por que abrir-me sob teu corpo?' Talvez aqui houvesse uma resposta feita de silêncio ou perplexidade 
por parte do companheiro. Mas Lilith insiste: ‘- Por que ser dominada por voce?

Contudo eu também fui feita do pó e por isto sou tua igual'. Ela pede para inverter as posições sexuais para estabelecer uma pariedade, uma harmonia que deve significar a igualdade entre os dois corpos e as duas almas. Malgrado este pedido, ainda úmido de calor súplice, Adão responde com uma recusa seca: Lilith é submetida a ele, ela deve estar simbolicamente sob ele, suportar seu corpo. (Sicuteri, 1986, p 35)

A função organizativa e imperativa inerente ao mito pode ser percebida neste ponto: “a mulher não aceita esta imposição e se rebela contra Adão. É a ruptura do equilíbrio. Qual é a ordem e a regra do equilíbrio? Está escrito: 'o homem é obrigado à reprodução, não a mulher"”. (Sicuteri, 1986, p 35).

Após este episódio, Lilith foge para o Mar Vermelho, região povoada por demônios, tornando-se também um ser demoníaco. Deus ordena que retorne a Adão, mas Lilith se nega. Deus ainda envia três anjos para resgatá-la que, por sua vez, nega-se novamente e então sofre as consequências de tal ato. Deus encarrega Lilith de se ocupar de meninos até o oitavo dia de vida7 e também de atormentar os homens durante o sono. Frente à desobediência de Lilith, os anjos voltam ao Éden e Deus determina que ela seria punida tendo seus filhos exterminados.

Assim, Lilith assume um papel de serpente demônio, usa de sua força destrutiva para seduzir e infernizar os homens e estabelece uma guerra entre criador e criatura. Não existe um fim para o mito já que ele ainda continua acontecendo na atualidade. Rodrigues (2007) explica que este mito simboliza a força sexual e psíquica feminina, que amedronta o universo masculino pela sensação de impotência que esta força lhes gera. Ainda a autora compreende que Lilith é a encarnação da amante sedutora, responsável pela desunião da família, aquela que "rouba o marido" ou mesmo também a figura da rebeldia da esposa que não suporta o não de seu "marido-Adão".

A desobediência de Lilith contra Adão e Deus levou à criação de Eva, tendo sido gerada da costela de Adão: "Esta é agora osso dos meus ossos, e carne da minha carne; esta

\footnotetext{
${ }^{7}$ A circuncisão é o símbolo da união do povo judeu a Deus. É realizada no 8o dia de nascimento do recémnascido quando este recebe oficialmente em uma cerimônia seu nome judaico
} 
será chamada varoa, porquanto do varão foi tomada" (Biblia, Gênesis, 2: 23). Apesar do mito de Lilith não ser reconhecido pelo cristianismo ortodoxo, Sicuteri (1986) considera que esta passagem é inequivocamente uma referência a uma mulher anterior. Ao contrário de Lilith, Eva era dócil e aceitava ser dominada por Adão. Contudo, seduzida pela serpente, desafia a Deus e come o fruto proibido. Teólogos modernos acreditam que Lilith encarna na história de Adão e Eva como demônio-serpente e convence Eva a comer o fruto proibido (Lopes \& Possebon, 2014).

A moral da história pode ser compreendida pelo título de Genesis 3 t: "A tentação de Eva e a queda do homem" (Bíblia, Gênesis, 3). Deus então decide punir Adão e Eva por tê-lo desobedecido. Adão se desculpa lançando sua falta sobre Eva, dizendo que o enganara e fora a causa de seu pecado. Eva, por sua vez, alega que a serpente a havia enganado. Deus castiga Adão determinando que a terra não produziria mais frutos, a não ser aqueles que fossem cultivados com o suor do seu rosto. À Eva foram dadas as dores do parto já que ela havia se deixado enganar pela serpente e atraído todos os males sobre o marido. Assim, Adão e Eva são expulsos do paraíso.

Mesmo Eva sendo mulher dócil e submissa, desafiou a Deus, comeu do fruto proibido e ainda seduziu o mais puro dos homes a pecar. Eva torna-se assim, cúmplice do mal, responsável pelos castigos da humanidade, pois ao seduzir o homem, tornou-se culpada pela sua desgraça e de todos os males humanos. Estruturalmente, Lilith e Eva cometeram o mesmo crime: desobedeceram o criador, que é também uma figura masculina.

Levando-se em consideração a tese de Levi Strauss de que os mitos apresentam funções organizativa, explicativa e compensatória, podemos entender a forma como é definido o papel da mulher na sociedade regida por um sistema patriarcal, tendo como pilar a religião, como sendo as funções organizativa e explicativa do mito de Lilith e Eva. A importância da narrativa do Gênesis - relato fundador da cultura judaico-cristã - é que, enquanto mito, este cumpre seu papel organizador e regulador das normas de convivência social, apresentando modelos que determinam a construção de identidades individuais e coletivas.

É interessante observar que essa estrutura de dominação do feminino pelo masculino, a partir da qual se estabelece a origem da ordem e da civilização, encontra-se num dos mais antigos mitos conhecidos: o mito de Marduk e Tiamat, da Babilônia, que tem ao menos 
5.250 anos de existência. Tiamat é uma entidade feminina, associada aos oceanos e descrita como uma serpente marinha ou dragão, que era adorada como mãe dos elementos quando a sociedade sumérica e babilônica cultuavam deidades femininas. Marduk é um deus homem, luminoso e resplandecente, de uma geração posterior. Há uma batalha entre os deuses e Marduk mata Tiamat, parte-a ao meio, criando os céus a partir de seu tórax e a terra e os seres que a habitam a partir de suas entranhas. Não se trata apenas de uma narrativa de transição do caos, representado pelo feminino, para o cosmos, representado pelo masculino, mas de uma história da transição para o patriarcado. De acordo com o teólogo Walter Wink (1998), "Marduque e Tiamat não é apenas uma história da origem do patriarcado, é a história da submissão violenta da mulher ao homem”. Assim como Lilith é castigada e transformada em demônio-serpente por recusar-se a ser submetida a um homem, Tiamat, também demônio-serpente, é assassinada para dar origem à dominação masculina do mundo.

Diferente do papel feminino no matriarcado, a visão patriarcal do que se define como feminino foi profundamente alterada (Quadros, 2005). O feminino passou a declinar de um conceito de mulher sagrada e geradora da vida para o de mãe, procriadora, submetida a um homem. É importante enfatizar que a passagem de uma cultura mais matriarcal para o modelo patriarcal não acontece repentinamente e que as histórias em torno de Lilith possuem raízes anteriores à consolidação do cristianismo, assim como o mito de Tiamat e diversos outros. O medo à mulher não é uma invenção cristã, como enfatiza Silva e Mandú (2007), mas uma construção que foi incorporada de forma intensa ao seu imaginário. A desigualdade dos sexos está na raiz da tradição bíblica que orienta a maior parte da população brasileira, em que o Homem é obra das mãos divinas e a Mulher das costelas do homem, tendo sida criado para ele. Enquanto o masculino se associa à orientação da pureza e benevolência de Deus, o feminino é associado aos desejos terrenos, à incontinência, portanto, ao diabo. Assim, a dominação masculina passa a ser justificada como positiva e moral, na medida em que se auto-afirma como sendo exercida para benefício do dominado e não por interesse do dominador:

É quase um favor que os homens, tão devotos, se dediquem a vigiar e guiar o sexo frágil, pelo qual, em louvor a Deus e ao bem da humanidade, devem responsabilizarse. É da submissão feminina que depende a harmonia do casal desde o primeiro 
instante da criação e se a preeminência masculina sobre as mulheres se embruteceu,

o foi por consequência direta e justa pela culpabilidade de Eva (Martins, 2009, p. 9).

Neste ponto podemos compreender um pouco melhor o "desaparecimento" do mito de Lilith dos escritos do cristianismo ortodoxo. A personalidade culpada e oprimida de Eva veio sobrepor a insubordinação, independência e sensualidade de Lilith. A autonomia do desejo feminino foi e ainda é vista com maus olhos. Trazendo o mito para atualidade, ainda percebemos exigências de que mulheres tenham comportamentos tradicionais, recatados, obedientes e que adaptem suas atividades cotidianas à realidade moderna. E esses comportamentos tradicionais ainda incluem a submissão à figura masculina, sob pena da mulher receber inúmeros títulos como desrespeitosa, vadia, vagabunda, puta ou prostituta, simplesmente por não estar sob os cuidados - entenda-se: o domínio - de um homem. Não ter a chancela de um homem, desde a antiguidade até os dias de hoje, pode ser lido como “estar disponível sexualmente”.

\section{Procedimentos Metodológicos}

Os caminhos metodológicos percorridos por este artigo se fundamentam na perspectiva qualitativa de pesquisa, visto que possuem uma base ontológica subjetivista (Rey, 2005). Esta escolha se deu considerando a possibilidade de diálogo mais efetivo com o objetivo deste trabalho, que se distancia da busca pela apreensão objetiva de uma realidade universal, ou da comprovação empírica ou positivista de uma hipótese. Pelo contrário, é importante salientar que o que se busca, neste sentido, é pensar nos relatos de vida de prostitutas da atualidade como meio de ilustrar possíveis relações entre a construção histórica da prostituição no contexto patriarcal e o valor simbólico da representação feminina em um mito religioso.

Dessa forma, parte-se do pressuposto de que as experiências vivenciadas por estas mulheres no decorrer de suas trajetórias de vida se entrelaçam psiquicamente com o contexto histórico e social no qual elas se situam (Lopes, 2013). Portanto, para o recolhimento das histórias, utilizou-se entrevistas semi-estruturadas inspiradas na 
metodologia de "história de vida", que foram gravadas, transcritas e analisadas tendo como base os fundamentos da psicossociologia.

Em termos práticos, os pesquisadores frequentaram a APROSMIG (Associação das Prostitutas de Minas Gerais) por 5 dias a fim de compreender a rotina das prostitutas que ali frequentavam. Todos os encontros ocorreram na sede da associação localizada no andar térreo de um dos hotéis. As entrevistas ocorriam com aquelas que se disponibilizavam conversar quando recorriam a associação em busca de preservativos, acompanhamento psicológico ou demais direcionamentos conferidos pelas coordenadoras em casos de necessidades médicas ou jurídicas.

Inicialmente, foram realizados encontros com cinco mulheres que trabalham como prostitutas em hotéis na rua Guaicurus em Belo Horizonte. Essas trabalhadoras desempenham suas atividades durante o período comercial e chegam por volta de sete horas da manhã para solicitar a chave de seus quartos. Conforme mencionado acima, dado o cenário legislativo concernente a esta atividade, este processo ocorre de forma informal e não normalizada, de modo que fica a cargo do dono do hotel deliberar quem poderá alugar os quartos ou não.

Tendo em vista a situação de trabalho ao qual o contato foi realizado, as entrevistas foram realizadas conforme a disponibilidade das prostitutas que se dispuseram a conceder um período do seu dia para relatar suas memórias e narrar algumas situações corriqueiras do trabalho. É importante ressaltar que a disponibilidade das entrevistadas foi um fator limitador para se aprofundar na metodologia "história de vida", já que precisam, independente do número de programas, arcar com as diárias do hotel.

Assim, mesmo considerando esse limitador, buscou-se ancorar as entrevistas realizadas nos pressupostos da metodologia história de vida realizando adaptações para as possibilidades que o contexto impôs aos pesquisadores. Assim, conduziu-se as entrevistas sugerido-se temas como infância, relacionamentos, trabalho, amizade, medos, vontades ou aspirações. É importante ressaltar que a escolha das mulheres entrevistadas não ocorreu tendo como objetivo alcançar uma representação generalizada da situação de qualquer prostituta, mas buscou elucidar vivências de algumas delas, assumindo sua singularidade, com a finalidade de ilustrar as relações vislumbradas neste artigo. 
É importante ressaltar que a "História de Vida" pode ser considerada como um método rico e amplo, porque a experiência de vida, em uma perspectiva psicológica, produz o conhecimento, não por meio de leis rígidas e definidas, pelo contrário, propõe-se a lidar com a subjetividade e o imaginário de sujeitos que constroem e são construídos pela história e sociedade. Há nessa metodologia uma preocupação em abordar a realidade preservando sua complexidade. Assim, é necessário "superar a ilusão de validade ou a legitimidade de um conhecimento por sua correspondência linear com dados factíveis, o que resultaria em fragmentação e simplificação da realidade social” (Lopes, 2013, p.65)

Por fim, a partir dessa linha de condução metodológica, parte-se para a apresentação das trajetórias de vida das prostitutas entrevistadas. Primeiramente, haverá uma exposição introdutória dos relatos recolhidos e então apresentaremos algumas possibilidades de interpretações acerca destes relatos.

\section{As mulheres entrevistadas}

Segundo Andrade e Teixeira (2004), a prostituição de baixo meretrício acontece em Belo Horizonte, desde sua concepção como cidade em 1897. A rua Guaicurus, assim como a avenida Oiapoque, desde o início da urbanização da cidade, já podiam ser destacadas por concentrarem uma relevante quantidade de cabarés. Até os dias de hoje, a rua Guaicurus é considerada um dos principais focos de zona de meretrício em Belo Horizonte, motivo pelo qual a pesquisa foi desenvolvida nesta região.

Foram coletadas cinco narrativas, as quais partem de alguns aspectos em comum. Muitas tinham mais de 40 anos e cresceram em uma época em que o país passava por um período de forte instabilidade econômica, sobretudo em regiões mais afastadas das grandes capitais. A pobreza e a miséria na infância foram fatos muito presentes no discurso dessas mulheres que viveram em favelas ou em cidades do interior:

Dandara $^{8}$ : Ah minha infância foi no interior né, que eu nasci no interior de Paraopeba. Era só miséria, pobreza, passava fome, ih! Fi duma égua! Que a gente morava na roça mesmo, meu pai tinha duas mulher né, muito pobre, sustentar duas mulher fica difícil.

\footnotetext{
${ }^{8}$ Para manter o sigilo do nome das entrevistadas optou-se por utilizar nomes fictícios inspirados em feministas brasileiras ou em mulheres com trajetórias notáveis no cenário nacional.
} 
Pagu: Ah, minha infância foi trabalhando, né... na roça, que eu sou do interior, da roça... aí foi trabalhando... trabalhando e ajudando minha mãe. (...) a vida sofrida, né... não tinha luxo nem nada... nunca tive condição.

Ainda sobre a infância, a criação dessas mulheres quando crianças foi conferida à figuras femininas ligadas à família: avó, tia ou a mãe. Uma delas casou-se aos 14 anos. Conforme as falas seguintes, pode-se perceber a ausência da figura paterna como uma situação comum na história das entrevistadas:

Elza: Praticamente eu não tive relação com meus pais, eu fui uma menina muito sozinha. Desde quando eu fui na minha adolescência quem me criou foi minha avó.

Luz del Fuego: Minha infância eu passei com a minha vó, aí depois que minha vó faleceu eu fui morar com a minha mãe (...) meu pai foi separado da minha mãe. Meu pai foi morar com a comadre da minha mãe.

A gravidez não programada, recorrente nas falas, foi um dos fatores que colaborou para a inserção dessas mulheres na prostituição. Assim, a necessidade de sustentar os filhos associada à falta de oportunidades de emprego no mercado formal foi um ponto levantado como justificativa para a procura desta forma de trabalho como um caminho para a solução dos problemas.

Luz del Fuego: Aí resumindo, eu fiquei com três menino pequeno, desempregada né. Aí eu tentei trabalhar em casa de família. Mas o dinheiro que eu ganhava era pra mim pagar armazém essas coisas assim sabe? Aí pensei assim: ai meu deus do céu como é que eu vou fazer. Aí eu falei assim, sabe como é que eu vou fazer? Eu vou ver se eu arrumo um lugar pros meus menino ficar, em casa de família né? Aí eu levei um menino meu, fui perguntar a dona: estou querendo arrumar meus menino pra ficar aqui de dia e eu trabalhar... Ela virou pra mim e falou assim, ó só tem pra você levar seus menino é em tal lugar você 
tem que pagar duas passagem e todo dia, ao todo seria quatro passagem. É assim que tem. (...)aí ela virou pra mim e falou assim: você tem quantos filhos? Ai eu falei assim, eu tenho três. Aí ela falou assim, da esse aí pra nós, que a gente doa ele, e fica só com dois, dois é mais fácil. Ela sabia que eu tava precisando sabe? Achou que eu ia aceitar. Eu só olhei pra ela assim e pensei comigo assim: quer saber de uma coisa, num vou pedir ajuda pra ninguém, eu vou se virar sozinha pra criar esses menino meu. Aí eu comecei, e... aí eu comecei a fazer, ir pro/pra praça, aí depois eu comecei a ir trabalhar na Paraná.

Cora Coralina: Porque eu tinha filho, eu engravidei, tinha, tenho uma filha... e estava sem emprego. Sem emprego, sem trabalhar. E chegou uma hora que eu só tinha o dinheiro do ônibus. E você procura, procura emprego, e você não acha, e aí olhando jornais eu via a, a... eu via os anúncios[de prostituição], aí um dia eu peguei e fui.

Como mostramos anteriormente, a origem da prostituição comercial esteve atrelada ao desenvolvimento de uma sociedade patriarcal em que a mulher que não estivesse vinculada a uma figura masculina era vista como prostituta. Há uma ligação entre esse contexto e a realidade das prostitutas entrevistadas, já que a maioria delas foi criada sem a assistência do pai, o que pode ter contribuído para uma condição de vida mais vulnerável. Muitas delas também não puderam contar com o apoio de seus parceiros na gravidez e sustento dos filhos, reduzindo, de certa forma, a possibilidade de escolha de sua profissão, tendo em vista a urgência financeira para a sobrevivência e criação das crianças. Ao se refletir sobre a inserção dessas mulheres no mercado de trabalho, é difícil saber quanto da escolha de se tornar prostituta é uma decisão pessoal ou uma indução social.

A condenação da mulher como pecadora ou impura, sobretudo quando sua existência não é legitimada pelo vínculo oficial com um homem, mostra-se principalmente no estigma direcionado a quem vive da prostituição, exercido pela sociedade de forma violenta e agressiva - o que causava, nas entrevistadas, medo de serem julgadas e um sentimento de vergonha. O peso dessa marginalização é, de algum modo, absorvido por elas e as leva, muitas vezes, a se esconder. Algumas dessas prostitutas não permanecem na mesma cidade 
por muito tempo como estratégia para evitar o envolvimento com outras pessoas e expor sua família por causa do trabalho. Em suas falas, há uma constante necessidade de autojustificação moral, como se a prostituição as reduzisse a um lugar em que o caráter e a moralidade são questionáveis. A autoafirmação pode ser percebida como uma forma de resistência à estigmatização social e ao rebaixamento dos sujeitos. Frequentemente, observou-se nas falas das entrevistadas uma preocupação - que é, aliás, uma atitude política fundamental - em desconstruir essa imagem negativa.

Além disso, a legislação relacionada à prostituição revelam-se evasivas, já que ao mesmo tempo em que não proíbem a prática, enxergam como ilegais as demais atividades que a circundam. Ou seja, é permitido às mulheres vender sexo, mas para isso, muitas vezes, elas precisam ingressar na ilegalidade para conseguir se estabelecer na atividade. Desse modo, o desamparo em termos de orientação e proteção trabalhistas pode contribuir para que essas mulheres se mantenham em situação de precariedade. Para além das questões trabalhistas relacionadas a esta atividade, é essencial pensá-la em termos de desigualdade social e de gênero, fator que colabora para reduzir as condições de escolha dessas mulheres frente ao mercado de trabalho e às oportunidades de sustento. A questão da prostituição é inseparável da defesa da autonomia da mulher em relação ao seu próprio corpo, bem como da igualdade de oportunidades e direitos em relação ao homem frente à sociedade e ao mercado de trabalho.

É importante notar, acima de tudo, que as vivências de sofrimento relatadas pelas prostitutas estão relacionadas à construção histórica do papel da mulher na sociedade patriarcal. Os relatos que frequentemente envolvem uma explicação da prostituição em função da falta da presença paterna ou do abandono do parceiro podem ser vistos como uma triste herança das mulheres gregas abandonadas pelos pais, as quais eram levadas a se prostituírem, ou das filhas virgens vendidas por homens pobres para evitar a escravidão, ou das mulheres assírias impedidas de usar o véu por não serem casadas e com isso serem consideradas prostitutas, públicas e indignas de respeito. Pensar a mulher casada como sendo o contrário da prostituta pode parecer uma dicotomia estranha em contextos e classes sociais em que a figura da mulher solteira emancipada e bem sucedida profissionalmente têm aparecido com mais frequência, no entanto, é uma oposição que continua fazendo sentido para muitas mulheres e que aparece frequentemente nas falas das entrevistadas: 
Luz del Fuego: Todo mundo que sabe que eu sou prostituta me respeita. Que eu já falei com vizinha que eu era prostituta. Isso quando eu comecei a entrar. Uma vizinha falou assim... Casada... Falou comigo: "você trabalha na onde?" Falei assim: "eu faço vida”. Que antigamente falava que fazia vida... não era? "Eu faço vida. Oh, mas não sei porque você assustou tanto". "É que você nem parece." [falou a vizinha] Sabe por quê? Porque elas achava que prostituta tinha que andar de shortinho curtinho, beber, ficar lá no bar com os marido dos outro. Não. A gente não precisa ser assim não né?

Dandara: Mas eu como prostituta ponho muita mulher casada no chinelo, eu acho que tenho muito mais classe, muito mais caráter que muita mulher casada.

A prostituta, nesse contexto, aparece como a mulher que sofre preconceito porque não tem um homem para si, mas oferece sexo a todos e, com isso, coloca em risco os casamentos alheios. A imagem da prostituta é múltipla, como mostra Cora Coralina em seu poema "Mulher da Vida", dedicado ao Ano Internacional da Mulher em 1975: por vezes, ela aparece como a mulher que protege a virgindade das moças, ao apagar o fogo dos rapazes o que justificou a estatização dos bordéis na Grécia, por exemplo -, "ela é a muralha que há milênios detém as urgências brutais do homem para que na sociedade possam coexistir a inocência, a castidade e a virtude"; por vezes ela é percebida como a vítima humilhada da violência masculina, pois "na fragilidade de sua carne maculada esbarra a exigência impiedosa do macho"; por vezes, ela é a imagem da exclusão e do abandono de uma sociedade injusta e desigual, "sem cobertura de leis e sem proteção legal, ela atravessa a vida ultrajada e imprescindível, pisoteada, explorada, nem a sociedade a dispensa nem lhe reconhece direitos nem lhe dá proteção".

Ainda, há uma imagem mais antiga da prostituta, como a mulher que desafia o poder masculino, que desafia um deus macho e o patriarcado, como a mulher que não se submete ao domínio de um homem e que, por isso, deve ser punida. $\mathrm{O}$ patriarcado não perdoa a insubordinação feminina - não é por acaso que sua ofensa preferida, feita a todas as mulheres que provocam o orgulho e a supremacia masculinos, sejam prostitutas os não, é 
"puta", ou "filha da puta". A imagem dessa mulher aparece nos primeiros mitos das sociedades patriarcais ocidentais, como o mito de Tiamat e como o mito de Lilith.

\section{Considerações finais}

A prostituição sempre foi uma questão controversa para diversos setores da sociedade, como a religião, a moral, o trabalho, os costumes, a saúde, a legalidade, a família e também para os movimentos feministas. Alguns destes defendem a abolição da prostituição, compreendendo-a como um ultraje machista à dignidade do corpo da mulher, que ofende os direitos humanos básicos. Outros, compreendem que tratar a prostituta apenas como vítima, incapaz de aderir à prostituição como uma escolha legítima, é perpetuar a tradição patriarcal que concebe a mulher como um ser passivo e incapaz de agir e tomar decisões por conta própria.

A opção pelas entrevistas como base metodológica para este trabalho vai na contramão dessa tendência: o que as mulheres são - ou melhor, o modo como as mulheres são percebidas - é frequentemente colocado acima do que as mulheres dizem e do que elas decidem. Entendemos que se o objetivo é pensar a respeito da prostituição, relacionando-a ao contexto patriarcal da nossa sociedade, a voz que protagoniza essa pesquisa deve ser a voz das prostitutas. A esse respeito, é importante notar que grande parte das mulheres entrevistadas para esse artigo, ainda que relacionassem sua opção pela prostituição com o abandono por alguma figura masculina, solicitaram enfaticamente que não gostariam de ser tratadas como vítimas e que a prostituição foi, para elas, uma escolha de vida.

Por outro lado, mesmo sendo uma escolha de vida, é possível perceber um conflito interno quando tocamos no assunto família. A maioria esconde a atuação profissional para evitar preconceitos e estigmas que cercam a prostituição. Todas entrevistadas revelam que a família, ou os filhos ocupam um lugar de grande valor - e isso nos remete a seguinte questão: tendo a imagem da puta como oposição da mulher "de família", um trabalho que envolve sexo torna ainda mais complexo esse conflito. A prostituta, escancara literalmente a "desordem" do papel que a mulher deveria assumir. Todos os xingamentos a fim de depreciar uma mulher remete a questão sexual: vagabunda, puta, vaca, cadela, galinha e outros inúmeros. A mulher dita "de família”, assexuada, deveria se resguardar ao lar e cuidar 
dos afazeres domésticos. Em uma cultura fortemente marcada por oposições binárias como bem e mal, fraco e forte, racional e irracional; ocupar um lugar fora do modelo esperado é viver à margem, ou seja, é ser desconsiderado dos âmbitos social, cultural, político e econômico. Essa marginalização pode ser compreendida não somente como uma violência incrustrada em todos níveis sociais em que as mulheres estão inseridas mas, também como um fator impulsionador dos abusos físicos, do tráfico sexual, dos feminicídios e principalmente da manutenção da desigualdade de gêneros.

As diversas formas de violência associadas à mulher são sustentadas pela perpetuação da relação de dominação e submissão. Essa relação, fruto da lógica do regime patriarcal é reforçada pelo sistema jurídico. Basta recorrer ao Código civil de 1916, o qual afirma que quando a mulher se casa, vários de seus direitos civis ficam restritos à autorização do marido. A discussão moral que gira em torno de legalização da prostituição e do aborto, bem como a ausência de tipificação de estupro no interior do casamento no Código Penal Brasileiro são alguns, dentre os muitos exemplos em que podemos compreender o privilégio do direito político dos homens sobre as mulheres.

Ao se pensar no recorte dos estudos organizacionais é importante lançar luz que este estudo não comunga com o convencional intuito administrativo de instrumentalizar um conhecimento, mas visa desvelar os complexos meios em que se constituem a dominação de sujeitos e a naturalização das desigualdades que os circundam. Em uma perspectiva crítica, a prática organizacional está muito além da elaboração de técnicas e estratégias que frequentemente se mostram falhas e insuficientes frente à imprevisibilidade da vida. Se para Souza, Costa e Pereira (2015) “toda organização é uma construção histórica, social e cultural envolvida por relações de poder", buscar superar a dicotomia teoria $\mathrm{x}$ prática na administração relaciona-se, acima de tudo, com a compreensão das razões pelas quais certas verdades são legitimadas e de que forma o próprio conhecimento técnico ou acadêmico tem corroborado para a primazia do discurso científico frente ao saberes práticos dos sujeitos em questão.

Trazer para a discussão a proposta de se compreender a articulação da construção histórica da prostituição no contexto patriarcal e suas conexões com o valor simbólico da representação feminina em um mito religioso é, ao mesmo tempo, problematizar e convidar o leitor a refletir sobre o papel que a mulher ocupa no social - o que inclui, portanto, todas 
as formas organizacionais em que a mulher está inserida. Essa problematização, quando se pensa no recorte da administração, não vem descolada em tempo algum de uma construção social carregada de um contexto patriarcalista e machista como fundamentou-se neste artigo. Ainda, é impossível ignorar suas implicações nesse contexto em que a violência contra a mulher é geralmente compreendida como um fenômeno natural, ainda que na realidade, se mostra como algo específico de sociedades patriarcais que se sustentam a partir de uma lógica perversa de dominação.

Recontar a história da prostituição é trazer à luz parte de como a própria história da mulher vem sendo construída. O mito de Lilith e a história bíblica de Adão e Eva foram entendidos aqui como um recurso da religião judaico-cristã para a manutenção dos estereótipos de submissão da mulher, da superioridade do homem e da conservação da "família tradicional". Esses resgates permitem compreender e desnaturalizar as condições que a mulher da sociedade ocidental está submetida. O ponto é que, ainda que as mulheres não sejam vítimas passivas e incapazes de agir, há um conjunto de forças sociais na base do patriarcado que faz com que as decisões tomadas por elas sejam, muitas vezes, uma resposta angustiada a determinadas circunstâncias recorrentes como as já discutidas ao longo deste trabalho. 


\section{Referências}

Andrade, L. T., \& Teixeira, A. E. (2004). A territorialidade da prostituição em Belo Horizonte. Cadernos Metrópole (11).

Atal, J. P., Nopo, H., \& Winder, N. (2010). Gender and Ethnic Wage gaps in Latin America at the turn of the Century. Inter-American Development Bank.

Barreto, L. C. (2008). Prostituição, gênero e sexualidade: hierarquias sociais e enfrentamentos no contexto de Belo Horizonte. (Dissertação de Mestrado, Faculdade de Filosofia e Ciências Humanas) Universidade Federal de Minas Gerais, Belo Horizonte.

Barros, L. A. (2005). Mariposas que trabalham: Uma etnografia da prostituição feminina na região central de Belo Horizonte. Jus Navigandi, 9(827).

Brasil (2002). Classificação Brasileira de Ocupações. Brasília: Ministério do Trabalho e Emprego.

Brasília (2012). Câmara dos Deputados. Projeto de Lei ordinária PL 4.211/2012. Regulamenta a atividade de profissionais do sexo. Recuperado de http://www.camara.gov.br/proposicoesWeb/fichadetramitacao?idProposicao=551899.

Braverman, H. (1987). Trabalho e capital monopolista. Rio de Janeiro: Guanabara, 3, 359-379.

Bullough, V. L., \& Bullough, B. (1987). Women and prostitution: A social history (p. 62). Nueva York: Prometheus Books.

Butler, J. (2004). Undoing gender . Oxfordshire: Routledge

Cao, L., \& Stack, S. (2010). Exploring terra incognita: Family values and prostitution acceptance in China. Journal of Criminal Justice, 38(4), 531-537.

Ceccarelli, P. R. (2008). Prostituição-Corpo como mercadoria. Mente E cérebro-sexo, 4. 
Conceição, K. C. S. S. (2007). A personagem feminina na obra de João Simões Lopes Neto: uma releitura do mito de Lilith. (Dissertação de mestrado, Programa de Pós-Graduação em Letras). Universidade Federal do Rio Grande, Rio Grande, Rio Grande do Sul.

Cox, T. (1992). The Badi: prostitution as a social norm among an untouchable caste of west Nepal. Contributions to Nepalese Studies, 19(1), 51-71.

Engelhard, S. (1997). O renascer de Lilith. Jungiana, Revista Brasileira de Psicologia Analítica. Amor, erostismo, paixão. 15.

Engels, F. (2009). A origem da família, da propriedade privada e do Estado. Clube de Autores.

Foucault, M. (1984) História da Sexualidade 2: O Uso dos Prazeres. Rio de Janeiro: Graal.

Gênesis. In Bíblia. Português. Bíblia sagrada: contendo o antigo e o novo testamento. Tradução de João Ferreira de Almeida. Rio de Janeiro: Sociedade Bíblica do Brasil, 1966. p.678-686.

Gomes, A. M., \& Almeida, V. P. (2007). O Mito de Lilith e a Integração do Feminino na Sociedade Contemporânea. Revista Ancora. 2.

Hirata, H. (2010). Emprego, responsabilidades familiares e obstáculos sócio-culturais à igualdade de gênero na economiaı. Índice, 45.

Hirata, H. (2014). Gênero, classe e raça Interseccionalidade e consubstancialidade das relações sociais. Tempo social, 26(1), 61-73.

Jaggar, A. M., Bordo, S. R., \& Freitas, B. L. (1997). Gênero, corpo, conhecimento. Rio de Janeiro: Rosa dos Tempos.

Lerner, G. (1986). The origin of prostitution in ancient Mesopotamia. Signs, 236-254. DOI: $10.1086 / 494218$

Lopes, K. T. C., \& Possebon, F. (2014). A Serpente Mítica: O Confronto Entre O Consciente E O Inconsciente Em Jung. Diversidade Religiosa, 4(2). 
Martins, N. S. (2009). A maldição das filhas de Eva: História de culpa e repressão ao feminino na cultura judaico-cristã. Anais do XVI Encontro Estadual de História. Joao Pessoa.

Matos, M. I., \& Soihet, R. (2003). O corpo feminino em debate. São Paulo: Editora UNESP.

Moreira, R. A. P. R. (2009). Prostituição de Rua: Um problema de saúde pública? Contributos para o seu estudo. (Dissertação de Mestrado, Medicina Legal). Universidade do Porto. Recuperado de https://repositorio-aberto.up.pt/handle/10216/7208

Oliveira, M. Q. (2008). Prostituição e trabalho no baixo meretrício de Belo Horizonte - O trabalho da vida nada fácil. (Tese de Doutorado). Universidade Federal de Minas Gerais, Belo Horizonte.

Osterne, M. D. S. F. (2012). A violência contra a mulher na dimensão cultural da prevalência do masculino. O público e o privado, (18).

Pereira, C. S. (2005). Lavar, passar e receber visitas. Cadernos pagu. 25, 25-54. DOI: 10.1590/So104-83332005000200002

Quadros, A. C. O. (2005). Câncer de mama: a cura pode estar em você. Brasília: Thesaurus.

Rodrigues, C. C. L. (2007). "Lilith e o arquétipo do feminino contemporâneo." Ética, religião e expressão artística. Anais do III Congresso Internacional de Ética e Cidadania.

Rodrigues, M. T. (2009). A prostituição no Brasil contemporâneo: um trabalho como outro qualquer. Revista Katálysis, 12(1), 68-76. DOI: 10.1590/S1414-49802009000100009

Sicuteri, R. (1986). Lilith. A lua negra. São Paulo: Paz e Terra.

Silva, M. A., \& Mandú, E. N. T. (2007) Ideias cristãs frente ao corpo, à sexualidade e contracepção: implicações para o trabalho educativo. Revista Gaúcha de Enfermagem, 28(4) 459p.

Souza, E. M. (2016). Fazendo e desfazendo gênero: a abordagem pós estruturalista sobre gênero. In A. P. Carrieri, J. C. Teixeira, \& M. C. R. Nascimento. Gênero e trabalho: 
perspectivas, possibilidades e desafios no campo dos estudos organizacionais. Editora Edufba.

Strauss, C. L. (1981). Mito e Significado. Lisboa: Edições 70 (ed. original, 1978).

Tavares, M. (2006). Prostituição: diferentes posicionamentos no movimento feminista. Recuperado de http://www.umarfeminismos.org/images/stories/pdf/prostituicaomantavares.pdf

Ullmann, R. A. (2005). Amor e sexo na Grécia Antiga. Porto Alegre: Edipucrs.

Wink, W. (1998). The powers that be: Theology for a new millennium. New York: Doubleday. 